\title{
Cenpestán
}

\section{Mapeamento das unidades de ensino superior em instituições multicampi: análise das proximidades tecnológicas no Centro Estadual de Educação Paula Souza}

\author{
Regina Ferreira da Rocha \\ Doutoranda; Universidade Estadual Paulista Júlio de Mesquita Filho, Marília, SP, Brasil; \\ regina.rfr2018@gmail.com \\ Maria Cláudia Cabrini Grácio \\ Doutora; Universidade Estadual Paulista Júlio de Mesquita Filho, Marília, SP, Brasil; \\ cabrini@marilia.unesp.br
}

\begin{abstract}
Resumo: As Instituições de Ensino Superior são consideradas pilares importantes ao desenvolvimento científico e tecnológico. Neste cenário, o Centro Estadual de Educação Tecnológica Paula Souza, instituição de ensino multicampi, é formado por 73 Faculdades de Tecnologia distribuídas no estado de São Paulo. Analisam-se as proximidades entre as unidades do Centro Paula Souza, segundo as vocações tecnológicas, a fim de visualizar agrupamentos (clusters) formados a partir das suas similaridades. Como aporte metodológico para mapear a rede de proximidades entre as unidades de ensino, adotam-se a análise de redes sociais e a análise estatística multivariada de cluster. Observam-se três agrupamentos, a partir dos quais é possível visualizar as potencialidades de interação entre as unidades, suas forças, seus aspectos comuns e suas peculiaridades. Os resultados oferecem aporte às tomadas de decisão da gestão acadêmico-científica da instituição, assim como um método de análise para outras com estrutura semelhante.
\end{abstract}

Palavras-chave: Clusters em Instituições de Ensino Superior Multicampi. Análise de Redes Sociais. Informetria.

\section{Introdução}

O desenvolvimento socioeconômico de uma nação está condicionado ao progresso científico e tecnológico, razão pela qual os países que buscam riquezas investem em Pesquisa e Desenvolvimento (P\&D). Deste modo, a produção científica torna-se fundamental e "ganha importância crescente como fator de impulsão da ciência, tecnologia, inovação e competitividade" (FUNDAÇÃO DE AMPARO..., 2010, p. 4-7). Sob essa perspectiva, Vanz et al. (2018) considera o setor universitário um dos principais motores do desenvolvimento científico e econômico de um país, fato que instiga a realização de estudos acerca do desempenho de instituições de ensino superior em nível nacional.

No Brasil, a estrutura do ensino superior está subordinada à legislação federal, a Lei de Diretrizes e Bases (LDB) de 1996 (BRASIL, 1996), que determina a natureza jurídica das instituições públicas ou privadas, além de marcos regulatórios. Tais instituições podem ser 
acadêmicas (universidades, centros universitários, faculdades integradas, institutos ou escolas superiores) ou tecnológicas (BRASIL, 2002). No âmbito das instituições estaduais públicas do Estado de São Paulo, encontram-se as universidades e instituições isoladas, além das Faculdades de Tecnologia ou Fatecs, vinculadas à Secretaria de Desenvolvimento Econômico (FUNDAÇÃO DE AMPARO..., 2010, p. 2-10; CENTRO ESTADUAL..., 2019).

Segundo o Relatório de Ciência, Tecnologia e Inovação em São Paulo, a modalidade de ensino superior tecnológico pode assumir um papel relevante para o desenvolvimento socioeconômico dos países, ao contribuir de forma direta para a qualificação profissional dos indivíduos diante das especificidades requeridas pelo mercado de trabalho (FUNDAÇÃO DE AMPARO..., 2010).

Dada a importância da formação acadêmica para a qualificação tecnológica profissional, há regiões em que se observa a ausência ou escassez de mão de obra desta natureza, particularmente naquelas com vocação industrial. Neste sentido, Azevedo-Ferreira e Motta (2016) realizaram o mapeamento informétrico para identificar o perfil da oferta tecnológica acadêmica na mesorregião do sul fluminense. Constatou-se, então, o empenho da Universidade Federal Fluminense para alinhar a oferta às necessidades tecnológicas do mercado, considerando as demandas e aptidões locais.

Com a proposta de atender à demanda por cursos tecnológicos, o Centro Estadual de Educação Tecnológica Paula Souza (CEETEPS), autarquia vinculada à Secretaria de Desenvolvimento Econômico, está presente em 321 municípios do estado de São Paulo. A instituição oferece cursos de graduação em 73 Faculdades de Tecnologia (Fatecs), instaladas em 66 municípios, acolhendo um público superior a 84 mil alunos, matriculados em 77 cursos, distribuídos em 10 eixos de áreas específicas (CENTRO ESTADUAL..., 2019). Arcabouço organizacional parecido é explorado por Carvalho, Oliveira e Lima (2018) e Nez (2016), que nomeiam essa estrutura como multicampi (também referenciado na literatura como multicampus). Para esses autores, trata-se de um modelo diferenciado de universidade que deve ser visto pela ótica da complexidade dos aspectos estruturais, acadêmicos, pedagógicos e de gestão.

Frente à estrutura organizacional do CEETEPS, no que se refere às atividades acadêmicas das diversas unidades de Fatecs, suas ações e decisões envolvem docentes/alunos e cidadãos que carecem de informações relevantes.

Neste estudo, objetiva-se visualizar e analisar a rede das Faculdades de Tecnologia do CEETEPS, de modo a compreender sua composição, ou seja, investigar suas proximidades 
em relação aos cursos por elas oferecidos, visando entender a dinâmica de oferta de cursos tecnológicos e suas afinidades com unidades com características similares.

No CEETEPS, assim como nos demais segmentos de negócios, entre os aspectos norteadores de suas atividades, encontra-se a missão, que consiste em promover a educação pública profissional e tecnológica dentro de referenciais de excelência, visando o desenvolvimento tecnológico, econômico e social do estado de São Paulo (CENTRO ESTADUAL..., 2019). Dessa forma, o mapeamento das unidades de Ensino Superior do CEETEPS é interessante para entender sua dinâmica organizacional.

A justificativa para a realização do presente estudo parte da importância da Instituição de Ensino Superior (IES) para o desenvolvimento socioeconômico, sendo necessária a compreensão de suas atividades acadêmicas, suas potencialidades e seus aportes. Outro fator interessante é o desenvolvimento de conhecimento tecnológico que pode se sobrepor àqueles gerados em outras Unidades, não necessariamente próximas geograficamente, favorecendo o intercâmbio entre os atores das instituições. Há, ainda, questões relativas ao planejamento estratégico da IES no que diz respeito a sua dinâmica. Neste sentido, Bonaccorsi, Daraio e Simar (2006) debatem a noção de universidade como padrão emergente de configuração de resultados que dependem da tomada de decisão autônoma percebida pelas contribuições que instituições desta natureza oferecem à sociedade.

O cenário é fértil para a realização de estudos nesse escopo, dentre os quais quatro são destacados. O primeiro, realizado por Carvalho, Oliveira e Lima (2018), explora a avaliação institucional em uma universidade pública brasileira multicampi e suas contribuições na melhoria da gestão. Outro estudo, desenvolvido por Garcia e Matias (2019), analisa a rede de conexões estabelecidas, por menções via web entre os Institutos Federais de Educação, Ciência e Tecnologia (IF) e as universidades públicas, ambos da região Sul do Brasil. Observa que há uma intensa conexão entre as unidades, a centralidade da unidade de Santa Catarina frente as demais, além disso, evidencia a existência de agrupamentos institucionais que supostamente favorecem o fortalecimento dos laços entre as instituições mais próximas.

Um terceiro estudo nesse escopo foi desenvolvido por Nez (2016). Com o intuito de compreender os dilemas da gestão do modelo de instituições universitárias multicampi localizadas no estado de Mato Grosso, a autora se debruçou na pesquisa documental e em entrevistas a ex-pró-reitores e líderes de grupos de pesquisa. Apurou que há vantagens na multicampia, porém a dispersão geográfica gera dificuldades de natureza administrativa. Ao refletir acerca da natureza do modelo de IES multicampi, deve-se considerar o benefício da 
interiorização da Educação Superior, além de instituir a autonomia da Unidade. Dessa forma, cada Unidade deve ter características administrativas peculiares, administrar seus recursos, regular suas particularidades acadêmicos-científicas, estabelecendo, assim, a integração e o relacionamento junto ao contexto regional visando o desenvolvimento econômico, social e cultural (LAUXEN; 2006).

Bampi e Diel (2013) correlacionaram o modelo multicampi e suas relações com a sociedade e concluem que tal estrutura ameniza o caminho excludente, proporcionando maior equidade de acesso à educação superior, com o objetivo de definir mecanismos que desenvolvam oportunidades à região.

Esses estudos destacados evidenciam a relevância e pertinência da presente pesquisa.

$\mathrm{Na}$ análise da rede estrutural de Instituições de Ensino multicampi, ao considerar os elementos que desvendam suas peculiaridades, há que se pensar sobre a existência de agrupamentos de docentes/ pesquisadores, bem como de alunos com interesses específicos que contribuem para o crescimento das organizações e que são importantes ao desenvolvimento de determinadas regiões.

Metodologicamente optou-se pela análise de redes sociais e a análise estatística multivariada de cluster. Nesse contexto, considera-se que ao mapear a rede do CEETEPS várias vertentes de estudo podem ocorrer de forma a desvendar cenários que favoreçam o entendimento da dinâmica organizacional e socioeconômica.

\section{Arcabouço teórico}

É incontestável, há décadas, a exigência de incremento na produção de conhecimento. As mudanças sociais influenciadas pelas Tecnologias da Informação e da Comunicação (TIC) requerem a produção de conhecimentos em vários âmbitos - socioeconômicos, culturais e políticos (SANTANA, et al., 2014). Frente a essa questão, a fundamentação teórica está pautada na análise de redes e os agrupamentos emergentes entre seus atores, decorrentes das proximidades resultantes da sua característica constitutiva sob análise, visto ser o mapeamento de redes um procedimento significativo para o processo de descoberta de potenciais agrupamentos. Ressalta-se que a emersão dos agrupamentos contribui para a visualização de características peculiares em comum entre as Unidades, propiciando o fluxo e troca de informações acadêmicas, científicas, de gestão e serviços entre elas.

Por volta da década de 1930, pesquisadores das áreas de psicologia e sociologia desenvolveram estudos sobre as redes sociais e, na década de 1950, houve a incorporação de 
ferramentas e conceitos matemáticos, como a teoria dos grafos e computacionais, fato que provocou a evolução contínua do tema (SCOTT, $2004^{1}$ apud HILÁRIO; GRÁCIO, 2011).

Uma rede social pode ser entendida como um conjunto de atores e de ligações entre eles (NEWMAN, 2001; WASSERMAN; FAUST, 1994; OTTE; ROSSEAU, 2002). Corroborando sua relevância, Cruz et al. (2011) citando Hanneman e Riddle (2005), consideram que os estudos que descrevem redes sociais evidenciam contornos em uma população. As ligações entre os atores de uma rede são decorrentes das relações estudadas, representando os caminhos que ligam dois ou mais atores (WASSERMAN; FAUST, 1994; CRUZ et al., 2011). Newman (2001) observa que é possível construir uma rede social para empresas, escolas, universidades ou outras comunidades quaisquer que sejam. Para Tomáel e Marteleto (2006, p. 75), "as redes sociais expressam o mundo em movimento", o qual ainda não se conhece (MOLINA; AGUILAR, 2004).

Na visão de Marteleto (2001), a Análise de Rede Social (ARS) é o meio para realizar a análise estrutural visando explicar os fenômenos a partir da forma da rede. A ARS é um procedimento de análise interdisciplinar, desenvolvido pela confluência de diversos campos, principalmente da Sociologia, da Matemática e da Ciência da Computação, para a análise da estrutura social de um grupo. Tal análise tem sido aplicada em muitas áreas do conhecimento (GRÁCIO; OLIVEIRA, 2010).

Em especial na área de Ciência da Informação, os estudos das redes sociais têm sido intensificados, particularmente, como método investigativo para a construção do conhecimento (HILÁRIO; GRÁCIO, 2011). Granovetter (1973) afirma que os estudos acerca da ARS podem ser considerados pertinentes à Ciência da Informação por representar a comunicação entre atores para a obtenção de informações vantajosas.

A ARS está sedimentada no estudo que mensura, descreve e analisa as variáveis relacionais de um conjunto de atores a fim de retratar a estrutura desse grupo (WASSERMAN; FAUST (1994), OTTE; ROSSEAU, (2002)), com ênfase nas ligações existentes entre eles, de modo a visualizar o fluxo de informação em uma estrutura social, os personagens significativos e a mediação e/ou centralização das informações que nela circulam.

Para Newman (2001), os atores e as ligações podem ser visualizados em diferentes caminhos, a depender da questão de interesse que permeia os indivíduos (atores), sejam eles pessoas, departamentos, unidades de uma instituição, municípios ou países, entre outros, e da relação analisada entre eles, material ou imaterial; por exemplo relação de amizade, de 
negócios, de colaboração científica, de cocitação, de ocorrência de uma característica em comum, entre outras. Ademais, uma relação pode ser ativa, isto é, a ligação entre os atores ocorrer voluntariamente, como é o caso da relação de amizade ou de colaboração científica. Por outro lado, a relação pode ser passiva, isto é, a ligação ocorrer independentemente do desejo dos atores, como é o caso da ligação de cocitação ou das redes por semelhança quanto a características em comum.

Morfologicamente, as redes possuem quatro elementos: os nós, as posições, as ligações e os fluxos, assim conceituados: (1) nós - conjunto de agentes (ou atores), objetos ou eventos/atividades presentes na rede em questão; (2) posições - localização dos nós no interior da estrutura, os quais estão diretamente associados à divisão do trabalho entre os diferentes agentes; (3) ligações - as conexões entre os nós da rede, e (4) fluxos identificados pela natureza específica do que circula pelos canais de ligação entre os nós, os quais podem ser tangíveis (insumos e produtos) ou intangíveis (informações) (BRITTO, 2002; OLAVE; AMATO NETO, 2001).

Na percepção de Otte e Rousseau (2002), a mensuração das propriedades das redes, como da distância entre os atores, cálculo dos indicadores de centralidade dos atores para a conexão da rede, entre outras, pode ser operacionalizada pela Teoria dos Grafos.

Ao refletir acerca do ambiente acadêmico-científico, Oliveira e Silva et al. (2006) afirmam que, em decorrência da flexibilidade do conceito de ator, a ARS é utilizada como ferramenta adicional aos estudos bibliométricos. Esses estudos avaliam os aspectos quantitativos da produção, disseminação e uso de informação científica, cujos resultados oferecem subsídios para a gestão e política científica, e informétricos, os quais avaliam aspectos quantitativos da produção, disseminação e uso da informação em geral. A designação atribuída a um ator pode ser um pesquisador, um artigo, uma citação, departamentos, unidades de uma instituição, áreas do conhecimento, periódicos, países, entre outros. No estudo de Oliveira e Silva et al. (2006), os atores (nós) correspondem aos professores do PPGCI/UFMG e as relações (ligações) correspondem às coautorias existentes entre eles, com a ARS contribuindo para a compreensão do funcionamento das comunidades científicas e dos colégios invisíveis, definidos como uma rede informal de comunicação com alguma forma de organização social. Nesses "colégios invisíveis", observa-se a presença dos indivíduos-chave de significativa importância para o fluxo da informação em uma área científica (ESCALONA-FERNANDEZ et al., 2012). 
Ao tratar das redes sociais, o termo agrupamento, ou cluster (termo em inglês, bastante utilizado na literatura nacional), se constitui como propriedade específica na modelagem das redes. Os atores constituintes das redes são agrupados, de modo que estes reúnam um contingente de indivíduos com afinidades (NEWMAN, 2001).

Amato Neto (2008, p. 56) destaca que os agrupamentos se tornam um grupo com habilidades específicas que favorecem a disseminação do conhecimento entre os atores e, consequentemente, no conjunto como um todo.

O conceito de agrupamento é utilizado por Bruni et al. (2019) a fim de caracterizar as IES europeias, distinguindo-as a partir da heterogeneidade observada em relação a indicadores e políticas do Ensino Superior relativas às suas produtividades. A perspectiva multinível combinou dados e análises da visão macro (nacional) e micro (institucional), possibilitando, também, a visualização de três agrupamentos. Concluíram que há limitações na abordagem unidimensional para verificar o desempenho das IES, considerando que a análise da produção científica ou do ensino é decorrente da natureza institucional e que as universidades especializadas em uma modalidade são mais eficientes em seus objetivos quando comparadas àquelas orientadas às duas atividades.

Destaca-se que no campo da Ciência da Informação (CI), observam-se, contemporaneamente, o uso da análise de agrupamento, ou análise de cluster, independente da ARS, como procedimento metodológico em pesquisas que buscam obter uma caracterização do universo, por meio da análise conjunta e simultânea de diversas variáveis. Entre elas, citam: Castanha e Grácio (2017) que empregam a análise estatística multivariada de cluster para identificar os agrupamentos dos programas de pós-graduação em CI, segundo seus indicadores de produtividade científica, e compará-los com os agrupamentos resultantes da atribuição das notas (conceitos) pela Coordenação de Aperfeiçoamento de Pessoal de Nível Superior (CAPES); Moraes e Souza (2017) que utilizam a análise de cluster e conceitos de análise de redes para visualização de produção científica de uma universidade, por meio de agrupamento e centralidade dos seus grupos de pesquisa; Gonzales, Martins e Melo (2018) que adotam a análise de cluster e análise multivariada para estabelecer uma tipologia que caracterize grupos distintos em relação à prática da gestão do conhecimento. 


\section{Metodologia}

A realização de uma pesquisa deve envolver um conjunto de ações e de propostas que possibilite a solução de um problema baseada em procedimentos racionais e sistemáticos (GIL, 2010).

Nesse sentido, adotou-se a ARS, entendida como comunidades interligadas que estabelecem algum tipo de relação entre seus pares. Dentre os vários elementos de uma rede, a um deles atribui-se a designação ator. Para Hilário e Grácio (2011), os atores de uma rede podem ser de naturezas diversas, como alunos, pesquisadores, instituições, países, entre outros.

Nesta pesquisa, os atores correspondem às Fatecs do Centro Paula Souza e as ligações são formadas a partir da coparticipação em eixos tecnológicos aos quais seus cursos pertencem, o que possibilita visualizar o acoplamento temático das instituições e identificar potenciais proximidades científicas a partir das áreas do conhecimento em comum em que atuam na formação de recursos humanos, representadas pelos cursos de graduação oferecidos. A ARS fornece introspecção dentro do ambiente organizacional como um todo, revelando as unidades de ensino melhor conectadas ou com maior centralidade em relação às características estudadas (ESCALONA-FERNANDEZ et al., 2012).

A informetria, método do rol das ferramentas métricas, é escolhida como parte da construção deste estudo. Segundo Santin (2011, p. 119), a informetria pode contribuir para o alcance de "uma visão global das estruturas do conhecimento e dos conjuntos sociais que promovem sua comunicação, de forma a possibilitar o acompanhamento e a avaliação dos fenômenos relacionados à informação", ressaltando que "sua utilidade é válida para complementação e não substitui a avaliação qualitativa".

Foram coletadas, no site institucional do CEETEPS, em 10 de agosto de 2019, as informações pertinentes aos eixos tecnológicos e seus cursos. Na sequência, recuperam-se também os cursos existentes nas 73 Fatecs. Os dados levantados foram registrados em planilhas do Excel. O Quadro 1 apresenta os dez eixos tecnológicos em que CEETEPS oferecem formação superior tecnológica no Estado de São Paulo e os respectivos cursos oferecidos em suas unidades. 
Quadro 1 - Eixos tecnológicos e respectivos cursos

\begin{tabular}{|c|c|c|c|}
\hline & $\begin{array}{c}\text { CONT ROLE E PROCE SSOS } \\
\text { INDUST RIAIS }\end{array}$ & & GE STÃO E NEGÓCIOS \\
\hline & Anallise de Proces sos Industriais & & Automação de Escritórios e Secretariado \\
\hline & Automação Inđustrial & & Comércio Exterior \\
\hline & E1etrônica Autom otiva & & Gestão Comercial \\
\hline & E1etrônica Industrial & & Gestão Empresarial \\
\hline & Gestão da Produccão Industrial & & Gestão de Energia e Eficiência Energética \\
\hline & Instalações Elétricas & 4 & Gestão Financeira \\
\hline & Maruffatura Avançada & & Gestão de Negócios e Inovação \\
\hline & Maruutenção de Aeronaves & & Gestão de Recursos Hum anos \\
\hline & Marutenção Industrial & & Gestão de Serviços \\
\hline & Mecânica Automobilistica & & Logistica \\
\hline 1 & Mecânica de Precisão & & Logistica Aeroportuária \\
\hline & Mecânica - Modalidade Processos de Produção & & Marketing \\
\hline & Mecânica - Modalidade Proj etos & & Secretariado \\
\hline & Mecânica-Processo de Soldagem & & \\
\hline & Mecanização em Agricultura de Precisão & & AMBIENTE E SAÚDE \\
\hline & Mecatrônica Industrial & & Gestão Ambiental \\
\hline & Microeletrônica & 5 & Hidráulica e Saneamento Ambiental \\
\hline & Processos Metalúrgicos & & Meio Ambiente e Recursos Hidricos \\
\hline & Processos Quimicos & & Radiologia \\
\hline & Prođução Industrial & & Sistemas Biomédicos \\
\hline & Projetos de Estruturas Aeronáuticas & & \\
\hline & Soldagem & & INFRAESTRU TURA \\
\hline & & & Construção Civil - Modali dade Edificios \\
\hline & PRODUCCÃO INDUST RIAL & & $\begin{array}{l}\text { Construção Civil - Movim ento de Terra e } \\
\text { Pavimentação }\end{array}$ \\
\hline & Biocombustiveis & 6 & Construção de E dificios \\
\hline & \begin{tabular}{|l} 
Construção Naval \\
\end{tabular} & & Controle de Obras \\
\hline & Cosméticos & & Gestão Portuária \\
\hline & \begin{tabular}{|l|} 
Desenvolvimento de Produtos Plásticos \\
\end{tabular} & & Sistemas Navais \\
\hline 2 & Fabricação Mecânica & & Transporte Terrestre \\
\hline & Materiais & & \\
\hline & Polimeros & & RECURSOS NATURAIS \\
\hline & Produção Têxtil & 7 & Agronegócio \\
\hline & Projetos Mecânicos & & Produção Agropecuária \\
\hline & Refrigeração, V entilação e Ar Condicionado & & Silvicultura \\
\hline & Têxtil e Moda & & \\
\hline & & & PRODUCCÃO ALIME NTÍCIA \\
\hline & INFORMAC̨ÃO E COMU NICAC̣ÃO & 8 & Agroindústria \\
\hline & Análise e Desenvolvimento de Sistemas & & Alimentos \\
\hline & Banco de Dados & & \\
\hline & Big Data no Agronegócio & & HOSPITALIDADE E LAZER \\
\hline & Design de Midias Digitais & 9 & Eventos \\
\hline 3 & Geoprocessam ento & & Gestão de Turismo \\
\hline & Gestão e Tecnol ogia da Inform ação & & \\
\hline & Informática para Negócios & 1 & PRODUCCÃO CULTURAL E DESIGN \\
\hline & Jogos Digitais & 0 & Produção Fonográfica \\
\hline & Redes de Computadores & & \\
\hline & Segurança da Irformação & & \\
\hline & Sistem as para Internet & & \\
\hline
\end{tabular}

Fonte: Elaborado pelas autoras, baseado em CEETEPS (CENTRO ESTADUAL..., 2019).

Na sequência, inicialmente, procedeu-se o mapeamento da rede do CEETEPS, ou seja, das Fatecs, por meio da construção de uma matriz de adjacências $73 \times 10$, com a intensidade de graduações de cada uma das 73 Fatec em relação aos 10 eixos tecnológicos. A partir dessa matriz foi possível observar também o total de graduações e eixos em que as Fatec atuam. A 
seguir, a partir da ferramenta "Affiliations: convert 2-mode to 1-mode" dentro da categoria de procedimentos "Data" do Ucinet, gerou-se, a partir da matriz de adjacências, uma matriz quadrada e simétrica de tamanho $73 \times 73$ com a intensidade de similaridade entre as 73 unidades registradas em suas células. A intensidade de similaridade entre duas unidades do CEETEPS foi calculada a partir do número mínimo de cursos em comum em cada um dos 10 eixos tecnológicos. Este critério baseou-se no adotado em Grácio (2020) em que são analisadas as proximidades entre autores. A construção da rede foi viabilizada pelo software Ucinet, versão 6.

A fim de identificar os agrupamentos das unidades do Centro Paula Souza, em função das similaridades entre elas, aplicou-se a análise estatística multivariada de agrupamentos (ou análise de cluster), com método Ward e medida de distância euclidiana quadrada. A análise estatística multivariada de agrupamentos permite identificar grupos de indivíduos a partir das proximidades relativas a um conjunto de variáveis analisadas simultaneamente (HAIR et al., 2009). Para a aplicação da análise de agrupamentos, as seguintes variáveis foram mensuradas simultaneamente em cada unidade: total de graduações oferecidas em cada um dos 10 eixos em que o CEETEPS atua. Para esse procedimento utilizou-se o software SPSS.

\section{Resultados e discussão}

A Tabela 1 apresenta as quantidades de cursos, de graduação e de municípios atendidos pelos 10 eixos de atuação tecnológica do CEETEPS. Destaca-se que as 278 graduações tecnológicas ofertadas para os 77 cursos, além de estarem atreladas aos eixos, são oferecidas por unidades específicas, considerando a vocação local e regional.

A partir da Tabela 1, observa-se, inicialmente, que a principal vocação do CEETEPS está atrelada à formação de profissionais para atuar no campo da Controle e Processos Industriais (Eixo 1), Informação e Comunicação (Eixo 3) e Gestão e Negócios (Eixo 4), uma vez que os cursos nesses eixos tecnológicos correspondem a $60 \%$ dos cursos, reunindo $77 \%$ do total de graduações oferecidas nas unidades. O eixo tecnológico de Controle de Processos Industriais (Eixo 1) é aquele com a maior quantidade de cursos oferecidos pelo CEETEPS, presente em 33 municípios do Estado de São Paulo. Por outro lado, embora os eixos 3 (Informação e Comunicação) e 4 (Gestão e Negócios) não sejam aqueles com a maior quantidade de cursos distintos, as graduações estão presentes na maioria (71\%) dos municípios em que o Centro Paula Souza mantém unidade de Ensino Superior. 
Tabela 1- Número (\#) de cursos, graduações e municípios atendidos pelo CEETEPS, por eixo tecnológico.

\begin{tabular}{lccc}
\hline \multicolumn{1}{c}{ Eixo Temático } & $\begin{array}{c}\text { \#cursos } \\
(\%)\end{array}$ & $\begin{array}{c}\text { \#graduações } \\
(\%)\end{array}$ & $\begin{array}{c}\text { \#municí- } \\
\text { pios }\end{array}$ \\
\hline 1-Controle e Processos Industriais & $22(29 \%)$ & $54(19 \%)$ & 33 \\
2- Produção Industrial & $11(14 \%)$ & $21(08 \%)$ & 13 \\
3- Informação e Comunicação & $11(14 \%)$ & $82(30 \%)$ & 52 \\
4- Gestão e Negócios & $13(17 \%)$ & $77(28 \%)$ & 52 \\
5- Ambiente e Saúde & $5(06 \%)$ & $10(04 \%)$ & 10 \\
6- Infraestrutura & $7(09 \%)$ & $9(03 \%)$ & 6 \\
7- Recursos Naturais & $3(04 \%)$ & $11(04 \%)$ & 10 \\
8- Produção alimentícia & $2(03 \%)$ & $4(01 \%)$ & 3 \\
9- Hospitalidade e lazer & $2(03 \%)$ & $8(03 \%)$ & 8 \\
10- Produção Cultural e Design & $1(01 \%)$ & $1(0 \%)$ & 1 \\
\hline Total & $77(100 \%)$ & $278(100 \%)$ & 73 \\
\hline
\end{tabular}

Fonte: Elaborado pelas autoras, baseada em CEETEPS (CENTRO ESTADUAL..., 2019).

Graduações focadas nos eixos 2, 5, 6, 7, 8, 9 e 10 são oferecidas em até 11 (15\%) dos municípios e, embora sejam responsáveis por $40 \%$ dos cursos que compõem o rol de atuação do Centro Paula Souza, suas graduações perfazem somente $23 \%$ do total de graduações, o que indica que são eixos com uma menor participação na formação de recursos humanos que aqueles presentes nos eixos 1, 3 e 4. Destaca-se, ainda, o fato de o eixo 10 (Produção Cultural e Design) ser oferecido em apenas um município, evidenciando a maior especificidade deste eixo.

A Tabela 2 apresenta os cursos com maior quantidade de graduação oferecidas pelo Centro Paula Souza, por eixo tecnológico, a fim de visualizar o foco de formação de recursos humanos do Centro, assim como a robustez dos eixos. Destaca-se, inicialmente, o curso Análise e Desenvolvimento de Sistemas (ADS), oferecido dentro do eixo 3 (Informação e Comunicação), com a maior quantidade de graduações oferecidas pelo CEETEPS, presente em 36 Fatecs, correspondendo a 44\% das graduações oferecidas pelo eixo tecnológico e 12\% do total de graduações do Centro. Considera-se que o fato de o curso de Análise e Desenvolvimento de Sistemas ser o mais ofertado reforça o vigor e importância do eixo Informação e Comunicação dentro do Centro Paula Souza.

Dentro do eixo 1 (Controle e Processos Industriais), que concentra a maior (22) diversidade de cursos oferecidos, destaca-se a graduação em Gestão da Produção Industrial, presente em 12 unidades de ensino, correspondendo a $22 \%$ do total de graduação oferecidas neste eixo tecnológico. 
Tabela 2 - Cursos mais ofertados por eixo tecnológico, com frequência absoluta e relativa de graduação em relação ao total de graduações do eixo

\begin{tabular}{|c|c|c|}
\hline \multicolumn{2}{|c|}{ EIXOS } & Cursos mais oferecidos \\
\hline \multirow{2}{*}{$1-$} & \multirow{2}{*}{ Controle e Processos Industriais } & Gestão da Produção Industrial $(12 \cong 22 \%)$ \\
\hline & & Automação Industrial $(6 \cong 11 \%)$ \\
\hline $2-$ & Produção Industrial & Fabricação Mecânica $(4 \cong 19 \%)$ \\
\hline & \multirow{2}{*}{ Informação e Comunicação } & Análise e Desenvolvimento Sistemas $(36 \cong 44 \%)$ \\
\hline & & Gestão e Tecnologia da Informação $(13 \cong 16 \%)$ \\
\hline \multirow{2}{*}{ 4- } & \multirow{2}{*}{ Gestão e Negócios } & Gestão Empresarial $(22 \cong 29 \%)$ \\
\hline & & Logística $(18 \cong 23 \%)$ \\
\hline \multirow{2}{*}{$5-$} & \multirow{2}{*}{ Ambiente e Saúde } & Gestão Ambiental $(3 \cong 30 \%)$ \\
\hline & & Sistemas Biomédicos $(3 \cong 30 \%)$ \\
\hline \multirow{2}{*}{$6-$} & \multirow{2}{*}{ Infraestrutura } & Gestão Portuária $(2 \cong 22 \%)$ \\
\hline & & Transporte Terrestre $(2 \cong 22 \%)$ \\
\hline $7-$ & Recursos Naturais & Agronegócio $(9=82 \%)$ \\
\hline & \multirow{2}{*}{ Produção Alimentícia } & Agroindústria $(2 \cong 50 \%)$ \\
\hline & & Alimentos $(2=50 \%)$ \\
\hline & Hospitalidade e Lazer & Eventos $(6 \cong 75 \%)$ \\
\hline & Produção Cultural e Design & Produção Fonográfica $(1=100 \%)$ \\
\hline
\end{tabular}

Fonte: Elaborado pelas autoras, baseada em CEETEPS (CENTRO ESTADUAL..., 2019).

Quanto ao eixo 4 (Gestão e Negócios), dois cursos merecem destaque: Gestão Empresarial, presente em 22 Fatecs, e Logística, em 18 unidades, correspondendo respectivamente a $29 \%$ e $23 \%$ do total de graduações do eixo.

Considera-se significativo destacar o fato de os cursos mais oferecidos pelos eixos 8 (Produção Alimentícia) e 9 (Hospitalidade e Lazer), em números absolutos, ocorrerem com baixa frequência, correspondem à maioria dos cursos oferecidos pelo Centro Paula Souza, indicando que estes eixos são focados em poucas formações distintas, ou seja, apresentam uma maior especificidade em relação aos demais. Por fim, no eixo 7 (Recursos Naturais), destaca-se o curso de Agronegócios em nove Fatecs, correspondendo a quase totalidade das graduações oferecidas no eixo, o que se alinha à característica mencionada em relação aos eixos 8 e 9.

A Figura 1 apresenta o mapeamento da rede das 73 Fatecs com os 10 eixos tecnológicos em que o CEETEPS atua, em que os eixos estão representados por círculos coloridos e as unidades (Fatecs), por quadrados azuis. O tamanho das figuras geométricas é proporcional à quantidade de cursos, em que se destacam as 11 unidades que possuem entre 14 e seis cursos. As linhas representam as relações dos cursos oferecidos pelas unidades por eixo tecnológico. 
Figura 1 - Mapeamento das Fatecs e sua atuação por Eixo Tecnológico

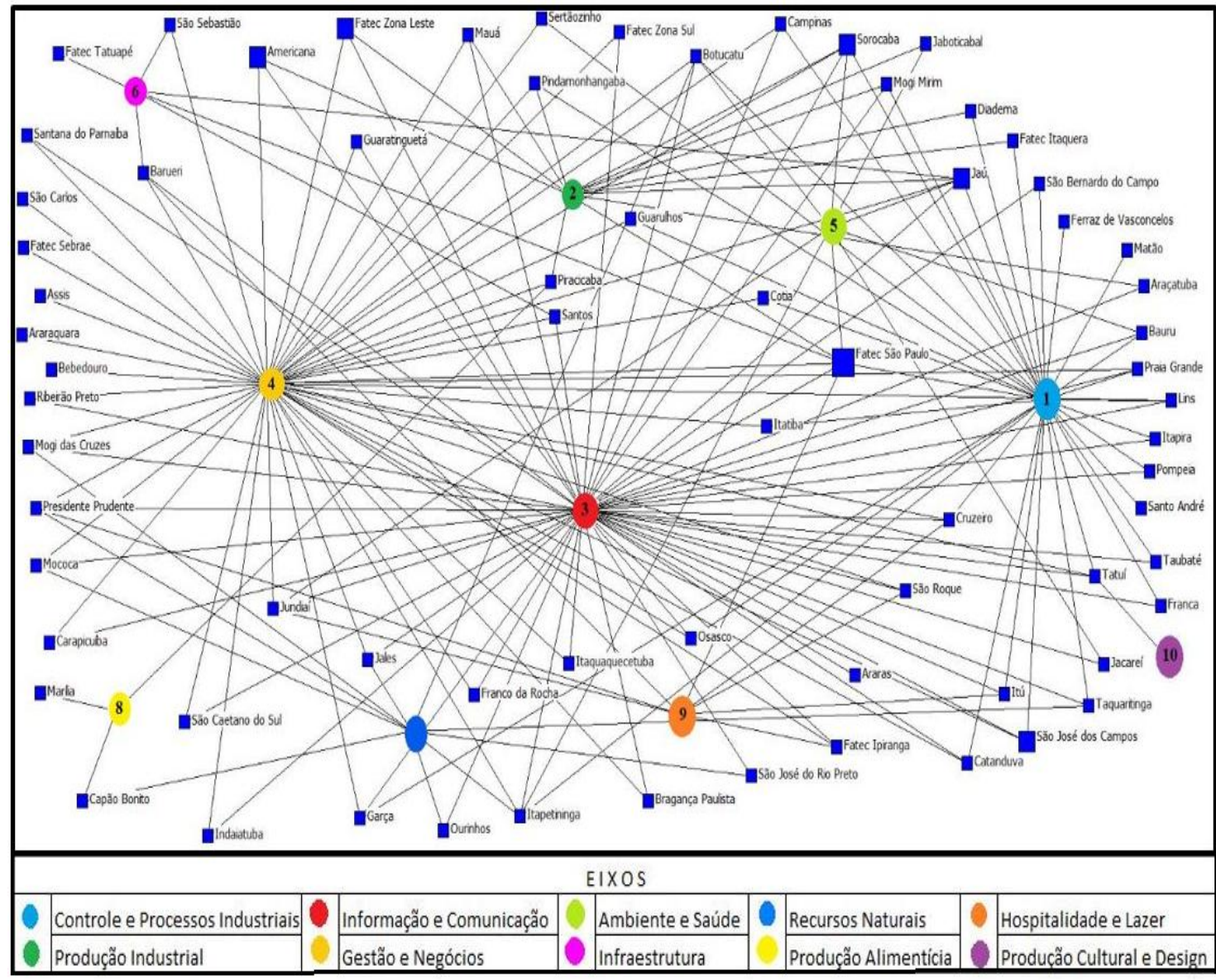

Fonte: Elaborado pelas autoras.

No mapeamento observa-se a posição central da Fatec São Paulo, ao oferecer 14 cursos, distribuídos em sete eixos, o que confere a esta unidade papel estratégico quanto ao seu significativo potencial para estabelecer parcerias acadêmico-científica com as outras unidades. Nesse sentido, mencionam-se também, em segundo lugar, a Fatec Sorocaba; em terceiro, a Fatec São José dos Campos e, em quarto estão a Fatec Jaú, a Fatec Zona Leste e a Fatec Americana, seguidas pelas cinco Fatecs que apresentam seis cursos cada uma. Quanto ao eixo tecnológico Produção Cultural e Design (Eixo 10), a única Fatec a ofertar um curso é a de Tatuí. O eixo Produção Alimentícia (Eixo 8) está presente nas Fatec Marília, Capão Bonito e Piracicaba.

Observa-se, assim, que a configuração da rede de atuação das unidades do Centro Paula Souza por eixo tecnológico (Figura 1) adere à observação de Hanneman e Riddle (2005) de que a análise de redes faz emergir limites em torno de uma população. Alinha-se, ainda, à afirmação de Escalona-Fernandez et al. (2012) de que a visualização das relações entre os atores em uma rede contribui para uma análise de introspecção do ambiente 
organizacional como um todo, ao revelar as unidades do CEETEPS com mais conexões tecnológicas ou mais centrais em relação às características estudadas.

A Figura 2 apresenta a visualização das localidades e proximidades geográficas dos cursos oferecidos pelo Centro Paula Souza, segundo os eixos tecnológicos, permitindo o entendimento da dinâmica de oferta dos cursos e a vocação local, além da escolha por candidatos a vagas nos referidos cursos. Possibilita, ainda, identificar a concentração dos cursos pelas regiões do estado e suas especificidades decorrentes da vocação mercadológica. Pela demarcação dos eixos oferecidos por região geográfica do mapa e na legenda lateral, encontra-se a relação das regiões/cidades e seus respectivos eixos.

A partir da Figura 2, observa-se que a distribuição geográfica das unidades do CEETEPS corresponde plenamente a apreciação de Carvalho, Oliveira e Lima (2018), de que o modelo multicampi favorece a interiorização da educação superior. Nesse sentido, destacase o fato de as IES multicampi precisarem adotar medidas administrativas que considerem as particularidades acadêmico-científicas das suas unidades, integrando-as ao todo, assim como ao contexto em que se inserem. Ademais, pode-se buscar ações que possibilitem a constituição de grupos de pesquisa e de redes de colaboração intra e inter unidades, segundo interesses acadêmico-científico e realidades similares. Nesse escopo, a proximidade geográfica de unidades com interesses e afinidades tecnológicas pode configurar um elemento facilitador da formação e concretização de grupos de pesquisa e parcerias interunidades. 
Figura 2 - Cursos oferecidos por eixo e proximidades geográficas

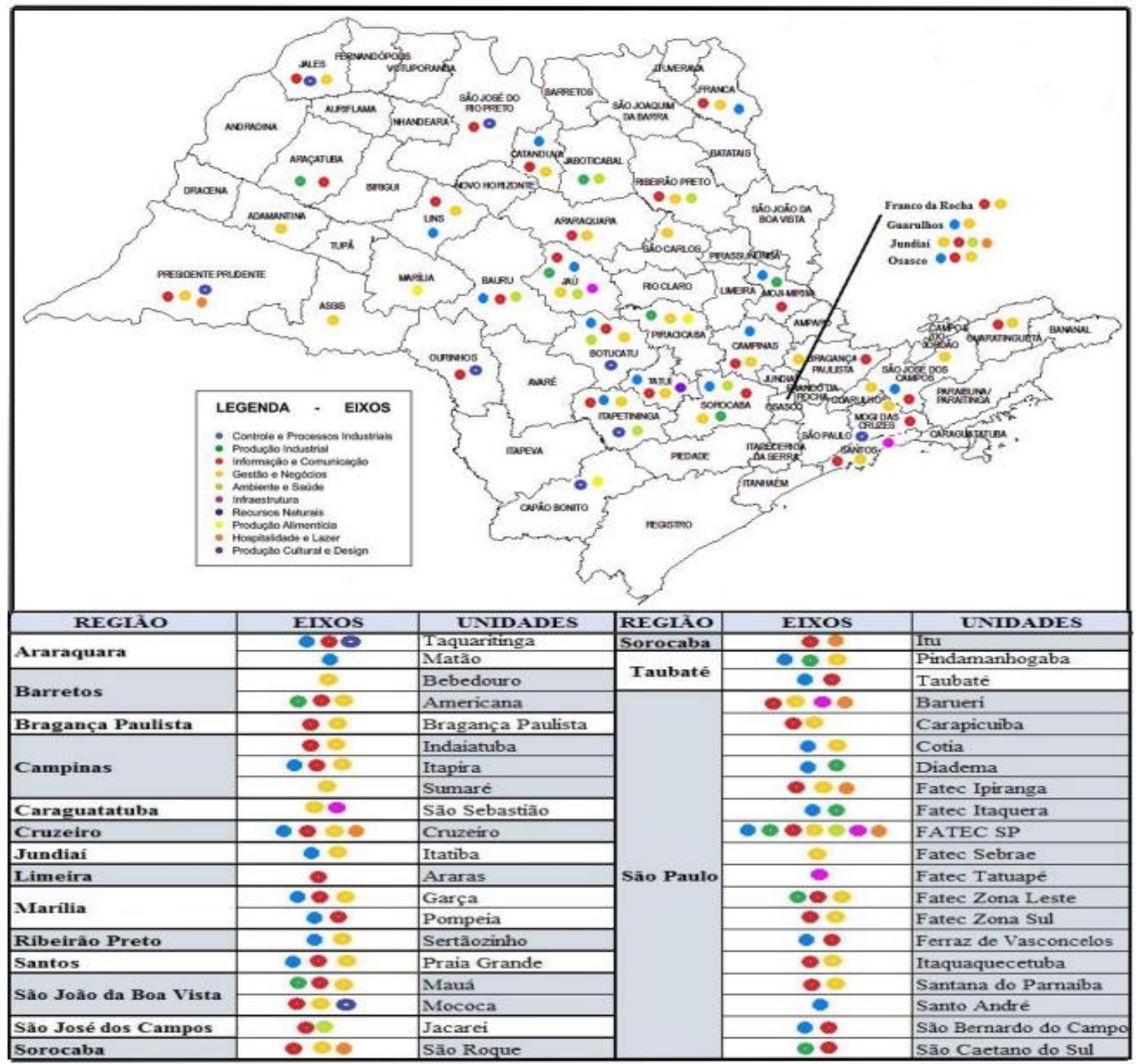

Fonte: Elaborado pelas autoras com base cartográfica de Mapas de São Paulo (20--).

A Tabela 3 apresenta os três agrupamentos das 73 Fatecs que compõem o CEETEPS, segundo a proximidade relativa aos eixos tecnológicos, a fim de compreender as similaridades entre as unidades, assim como seus distanciamentos em relação aos eixos em que atuam. Destaca-se, inicialmente, que a configuração dos grupos é resultante tanto da quantidade de cursos, quanto da variedade de eixos tecnológicos em que as unidades do CEETEPS atuam.

O agrupamento 1 (G1), maior grupo, constituído por 41 (56\%) unidades, concentra Fatecs periféricas em termos de intermediar ou centralizar o fluxo das ações colaborativas para a geração do conhecimento por ser aquelas que atuam em menos eixos: entre um e quatro eixos tecnológicos, com média igual a dois eixos tecnológicos. Além disso, oferecem baixa quantidade de graduações: entre um e cinco cursos, com média igual a três graduações. As 
unidades desse agrupamento atuam principalmente nos eixos 4 (Gestão e Negócios) e 3 (Informação e Comunicação), uma vez que a maioria (68\% e 59\%, respectivamente) delas oferece graduação alinhada a esses eixos temáticos. Destaca-se o subgrupo formado pelas unidades de número 9 a 14, no 16 e 24 a 33 (Tabela 3), com atuação simultânea nesses dois eixos. Além disso, as Fatecs de número 9 a 14 atuam também no Eixo 1 (Controle e Processos Industriais) e as unidades de número 24 a 30 e 33 oferecem também graduação no Eixo 5 (Ambiente e Saúde). Por outro lado, há dez Fatecs que atuam somente em um eixo.

O agrupamento G2 é formado por 24 unidades, nas quais são oferecidas entre três e sete graduações, média igual a cinco graduações e, em geral, pouca variação na quantidade de graduações entre elas. Essas graduações estão distribuídas entre dois e seis eixos tecnológicos, com média igual a três eixos. Essas unidades têm atuação de formação de recursos humanos centrada, especialmente no eixo tecnológico 3 (Informação e Comunicação), uma vez que todas as 24 unidades oferecem graduação a ele vinculado, e no eixo 4 (Gestão e Negócios), com 19 (79\%) das unidades formando profissionais nesse eixo. Particularmente, em relação ao eixo 3, salienta-se, ainda, o fato de, com exceção de Itapeva, Presidente Prudente e Fatec Zona Leste, todas as outras 21 unidade têm mais de um curso neste eixo. Além disso, suas unidades têm graduações pulverizadas por pelo menos mais um dos outros oito eixos tecnológicos.

Considera-se que uma característica discriminante entre os agrupamentos G1 e G2 é o fato de G2 ter mais robustez nos eixos tecnológicos 3 e 4, isto é, maior concentração de graduações nesses eixos e uma pulverização mais acentuada nos outros eixos. Em função dessa característica, considera-se que as Fatecs de G2 possuem intenso potencial de colaboração entre si e também com as Fatecs de outros agrupamentos, por atuarem em vários eixos com vários cursos. Salienta-se, todavia, que nenhuma Fatec deste agrupamento atua nos eixos 8 (Produção Alimentícia) e 10 (Produção Cultural e Design) e apenas três (13\%) atuarem no eixo 6 (Infraestrutura). 
Tabela 3 - Agrupamentos (G) das Fatecs, segundo as proximidades dos eixos em que atuam.

\begin{tabular}{|c|c|c|c|c|c|c|c|c|c|c|c|c|c|c|c|c|c|c|c|c|c|c|c|c|c|c|}
\hline & \multirow[b]{2}{*}{ Unidade } & \multicolumn{10}{|c|}{ Eixos } & \multirow[b]{2}{*}{$\begin{array}{c}\text { \#Gradua } \\
\text { ção }\end{array}$} & \multicolumn{12}{|c|}{ Eixos } & \multirow[b]{2}{*}{$\begin{array}{c}\text { \#Gradua } \\
\text { ção }\end{array}$} \\
\hline & & & 1 & 2 & 3 & 4 & 5 & 6 & 7 & 8 & 9 & 10 & & & Unidade & 1 & 2 & 3 & 4 & 5 & 6 & 7 & 8 & 9 & & \\
\hline \multirow{21}{*}{$\begin{array}{l}- \\
0 \\
0 \\
0 \\
0\end{array}$} & 1 & São Bernardo do Campo & 1 & 0 & 1 & 0 & 0 & 0 & 0 & 0 & 0 & 0 & 2 & 22 & Piracicaba & 0 & 1 & 0 & 1 & 0 & 0 & 0 & 2 & 0 & 0 & 4 \\
\hline & 2 & Taubaté & 1 & 0 & 1 & 0 & 0 & 0 & 0 & 0 & 0 & 0 & 2 & 23 & Itapira & 1 & 0 & 1 & 1 & 0 & 0 & 0 & 0 & 0 & 0 & 3 \\
\hline & 3 & Ferraz de Vasconcelos & 1 & 0 & 1 & 0 & 0 & 0 & 0 & 0 & 0 & 0 & 2 & 24 & lacareí & 0 & 0 & 1 & 0 & 1 & 0 & 0 & 0 & 0 & 0 & 2 \\
\hline & 4 & Pompeia & 1 & 0 & 1 & 0 & 0 & 0 & 0 & 0 & 0 & 0 & 2 & 25 & Cotia & 1 & 0 & 0 & 1 & 0 & 0 & 0 & 0 & 0 & 0 & 2 \\
\hline & 5 & Santana do Parnaiba & 0 & 0 & 1 & 1 & 0 & 0 & 0 & 0 & 0 & 0 & 2 & 26 & Araraquara & 0 & 0 & 1 & 1 & 0 & 0 & 0 & 0 & 0 & 0 & 2 \\
\hline & 6 & Itatiba & 1 & 0 & 0 & 1 & 0 & 0 & 0 & 0 & 0 & 0 & 2 & 27 & Osasco & 2 & 0 & 1 & 1 & 0 & 0 & 0 & 0 & 0 & 0 & 4 \\
\hline & 7 & Diadema & 1 & 1 & 0 & 0 & 0 & 0 & 0 & 0 & 0 & 0 & 2 & 28 & São Roque & 0 & 0 & 1 & 1 & 0 & 0 & 0 & 0 & 1 & 0 & 3 \\
\hline & 8 & Itaquaquecetuba & 0 & 0 & 1 & 2 & 0 & 0 & 0 & 0 & 0 & 0 & 3 & 29 & Campinas & 1 & 0 & 2 & 2 & 0 & 0 & 0 & 0 & 0 & 0 & 5 \\
\hline & 9 & São Sebastião & 0 & 0 & 0 & 2 & 0 & 1 & 0 & 0 & 0 & 0 & 3 & 30 & Praia Grande & 1 & 0 & 1 & 2 & 0 & 0 & 0 & 0 & 0 & 0 & 4 \\
\hline & 10 & Fatec Tatuapé & 0 & 0 & 0 & 0 & 0 & 3 & 0 & 0 & 0 & 0 & 3 & 32 & Matão & 1 & 0 & 0 & 0 & 0 & 0 & 0 & 0 & 0 & 0 & 1 \\
\hline & 11 & Catanduva & 1 & 0 & 1 & 1 & 0 & 0 & 0 & 0 & 0 & 0 & 3 & 32 & Tatui & 2 & 0 & 1 & 1 & 0 & 0 & 0 & 0 & 0 & 1 & 5 \\
\hline & 12 & Mogi das Cruzes & 0 & 0 & 1 & 2 & 0 & 0 & 1 & 0 & 0 & 0 & 4 & 33 & Franca & 1 & 0 & 1 & 1 & 0 & 0 & 0 & 0 & 0 & 0 & 3 \\
\hline & 13 & Fatec Ipiranga & 0 & 0 & 1 & 2 & 0 & 0 & 0 & 0 & 1 & 0 & 4 & 34 & Bebedouro & 0 & 0 & 0 & 1 & 0 & 0 & 0 & 0 & 0 & 0 & 1 \\
\hline & 14 & Fatec Zona Sul & 0 & 0 & 1 & 2 & 0 & 0 & 0 & 0 & 0 & 0 & 3 & 35 & Sumaré & 0 & 0 & 0 & 1 & 0 & 0 & 0 & 0 & 0 & 0 & 1 \\
\hline & 15 & Franco da Rocha & 0 & 0 & 1 & 1 & 0 & 0 & 0 & 0 & 0 & 0 & 2 & 36 & Adamantina & 0 & 0 & 0 & 1 & 0 & 0 & 0 & 0 & 0 & 0 & 1 \\
\hline & 16 & Ribeirão Preto & 0 & 0 & 1 & 1 & 1 & 0 & 0 & 0 & 0 & 0 & 3 & 37 & Assis & 0 & 0 & 0 & 1 & 0 & 0 & 0 & 0 & 0 & 0 & 1 \\
\hline & 17 & Araçatuba & 0 & 1 & 1 & 0 & 0 & 0 & 0 & 0 & 0 & 0 & 2 & 38 & Fatec Sebrae & 0 & 0 & 0 & 2 & 0 & 0 & 0 & 0 & 0 & 0 & 2 \\
\hline & 18 & Araras & 0 & 0 & 1 & 0 & 0 & 0 & 0 & 0 & 0 & 0 & 1 & 39 & São Carlos & 0 & 0 & 0 & 2 & 0 & 0 & 0 & 0 & 0 & 0 & 2 \\
\hline & 19 & Jaboticabal & 0 & 1 & 0 & 0 & 1 & 0 & 0 & 0 & 0 & 0 & 2 & 40 & Garça & 1 & 0 & 1 & 1 & 0 & 0 & 0 & 0 & 0 & 0 & 3 \\
\hline & 20 & Capão Bonito & 0 & 0 & 0 & 0 & 0 & 0 & 1 & 1 & 0 & 0 & 2 & 41 & Guarulhos & 1 & 0 & 0 & 3 & 0 & 0 & 0 & 0 & 0 & 0 & 4 \\
\hline & 21 & Marilia & 0 & 0 & 0 & 0 & 0 & 0 & 0 & 1 & 0 & 0 & 1 & & & & & & & & & & & & & \\
\hline \multirow{12}{*}{\multicolumn{2}{|c|}{$\begin{array}{l}4 \\
4 \\
4 \\
4 \\
4 \\
4 \\
4 \\
4 \\
5 \\
5 \\
5 \\
5\end{array}$}} & Cruzeiro & 1 & 0 & 2 & 1 & 0 & 0 & 0 & 0 & 1 & 0 & 5 & 54 & Jundiaí & 0 & 0 & 2 & 1 & 1 & 0 & 0 & 0 & 1 & 0 & 5 \\
\hline & & Fatec Zona Leste & 0 & 2 & 1 & 4 & 0 & 0 & 0 & 0 & 0 & 0 & 7 & 55 & Bauru & 1 & 0 & 2 & 0 & 1 & 0 & 0 & 0 & 0 & 0 & 4 \\
\hline & & Guaratinguetá & 0 & 0 & 2 & 4 & 0 & 0 & 0 & 0 & 0 & 0 & 6 & 56 & Indaiatuba & 0 & 0 & 2 & 4 & 0 & 0 & 0 & 0 & 0 & 0 & 6 \\
\hline & & Presidente Prudente & 0 & 0 & 1 & 1 & 0 & 0 & 2 & 0 & 1 & 0 & 5 & 57 & Itú & 1 & 0 & 2 & 0 & 0 & 0 & 0 & 0 & 1 & 0 & 4 \\
\hline & & Botucatu & 1 & 0 & 2 & 1 & 1 & 0 & 1 & 0 & 0 & 0 & 6 & 58 & Americana & 0 & 2 & 3 & 2 & 0 & 0 & 0 & 0 & 0 & 0 & 7 \\
\hline & & Itapetininga & 1 & 0 & 1 & 1 & 1 & 0 & 1 & 0 & 0 & 0 & 5 & 59 & Mauá & 0 & 3 & 1 & 1 & 0 & 0 & 0 & 0 & 0 & 0 & 5 \\
\hline & & São Caetano do Sul & 0 & 0 & 3 & 2 & 0 & 0 & 0 & 0 & 0 & 0 & 5 & 60 & Carapicuiba & 0 & 0 & 3 & 2 & 0 & 0 & 0 & 0 & 0 & 0 & 5 \\
\hline & & Mococa & 0 & 0 & 3 & 1 & 0 & 0 & 1 & 0 & 0 & 0 & 5 & 61 & Jaú & 1 & 1 & 2 & 1 & 1 & 1 & 0 & 0 & 0 & 0 & 7 \\
\hline & & Ourinhos & 0 & 0 & 3 & 0 & 0 & 0 & 1 & 0 & 0 & 0 & 4 & 62 & Jales & 0 & 0 & 2 & 1 & 0 & 0 & 1 & 0 & 0 & 0 & 4 \\
\hline & & São José do Rio Preto & 0 & 0 & 2 & 0 & 0 & 0 & 1 & 0 & 0 & 0 & 3 & 63 & Santos & 0 & 0 & 2 & 2 & 0 & 1 & 0 & 0 & 0 & 0 & 5 \\
\hline & & Taquaritinga & 1 & 0 & 2 & 0 & 0 & 0 & 1 & 0 & 0 & 0 & 4 & 64 & Barueri & 0 & 0 & 2 & 2 & 0 & 1 & 0 & 0 & 1 & 0 & 6 \\
\hline & 53 & Bragança Paulista & 0 & 0 & 2 & 2 & 0 & 0 & 0 & 0 & 0 & 0 & 4 & 65 & Lins & 1 & 0 & 4 & 1 & 0 & 0 & 0 & 0 & 0 & 0 & 6 \\
\hline \multirow{4}{*}{$\begin{array}{l}02 \\
0 \\
0 \\
0 \\
0\end{array}$} & 66 & Fatec Itaquera & 2 & 2 & 0 & 0 & 0 & 0 & 0 & 0 & 0 & 0 & 4 & 70 & Sertãozinho & 3 & 0 & $\overline{0}$ & 1 & $\overline{0}$ & $\overline{0}$ & 0 & 0 & 0 & 0 & 4 \\
\hline & 67 & Pindamonhangaba & 3 & 1 & 0 & 1 & 0 & 0 & 0 & 0 & 0 & 0 & 5 & 71 & Mogi Mirim & 2 & 2 & 1 & 0 & 0 & 0 & 0 & 0 & 0 & 0 & 5 \\
\hline & 68 & São José dos Campos & 4 & 0 & 3 & 1 & 0 & 0 & 0 & 0 & 0 & 0 & 8 & 72 & Sorocaba & 3 & 3 & 1 & 1 & 1 & 0 & 0 & 0 & 0 & 0 & 9 \\
\hline & 69 & Fatec São Paulo & 7 & 1 & 1 & 1 & 1 & 2 & 0 & 0 & 1 & 0 & 14 & 73 & Santo André & 3 & 0 & 0 & 0 & 0 & 0 & 0 & 0 & 0 & 0 & 3 \\
\hline
\end{tabular}

Fonte: Elaborado pelas autoras, baseada em CEETEPS (2019).

O agrupamento G3, com oito unidades, é formado com grandes Fatecs, uma vez que oferecem entre três e 14 graduações, com média igual a sete graduações. Além disso, em geral, essas Fatecs formam recursos humanos em diversos eixos tecnológicos (em média, três eixos tecnológicos), variando, todavia, entre um e sete eixos tecnológicos. Está centrado no eixo 1 (Controle e Processos Industriais), uma vez que todas as unidades de G1 oferecem graduação neste eixo. Por outro lado, nenhuma Fatec deste agrupamento atua nos eixos 
tecnológicos 7 (Recursos Naturais); 8 (Produção Alimentícia) e 10 (Produção Cultural e Design). Além disso, nos eixos 6 (Infraestrutura) e 9 (Hospitalidade e Lazer) há somente uma Fatec deste agrupamento atuando. Destaca-se, em G1, a presença da Fatec São Paulo, com 14 graduações, distribuídas por sete eixos temáticos, configurando a unidade com a presença mais vigorosa entre as 73 que constituem o CEETPS.

Em função da sua configuração, considera-se que o agrupamento G3 é aquele com o maior potencial para centralizar e intermediar ações colaborativas para a geração de conhecimento.

A Figura 3 apresenta a rede das 73 Fatecs, gerada a partir das suas proximidades (matriz de quadrada e simétrica $73 \times 73$ ), com a visualização dos três agrupamentos, segundo suas similaridades quanto a intensidade e dispersão de cursos oferecidos por eixo tecnológicos em que atuam (Tabela 3). Os agrupamentos estão descritos por cores; a saber: G1 em azul, G2 em verde e, por fim, G3 em vermelho. Destaca-se, como característica geral que norteou a configuração dos agrupamentos, o fato de que algumas unidades possuem uma quantidade mais elevada de cursos quando comparadas às outras, atuando em vários eixos e, algumas delas, em eixo(s) específico(s).

A partir da Figura 3, identificam-se sub-redes com especificidades muito significativas como a formada pelas Fatecs Marília, Capão Bonito e Piracicaba, componentes do agrupamento G1. Destaca-se a relevância desta sub-rede para a Fatec de Marília, uma vez que atua na formação de recursos humanos em um único eixo tecnológico (8 - Produção Alimentícia), que restringe, a princípio, seu potencial colaborativo dentro da rede organizacional como um todo. Destaca-se, ainda, a relevância da sub-rede do agrupamento G1 pelo formada pelas Fatecs Mogi das Cruzes, Guarulhos e Sumaré (conectadas pela atuação no eixo 4 - Gestão e Negócios) para a Fatec Sumaré, dado o fato de estarem sediadas em municípios circunvizinhos, viabilizando ações colaborativas locais e regionais, bem como a disseminação de conhecimentos específicos.

No agrupamento G2, destaca-se a sub-rede formada pelas Fatecs Bauru, Jaú e Botucatu, pela proximidade geográfica dos seus municípios sede e por todas atuarem simultaneamente nos eixos 1 (Controle e Processos Industriais), 3 (Informação e Comunicação) e 5 (Ambiente e Saúde). 
Figura 3 - Grupos por oferta de cursos

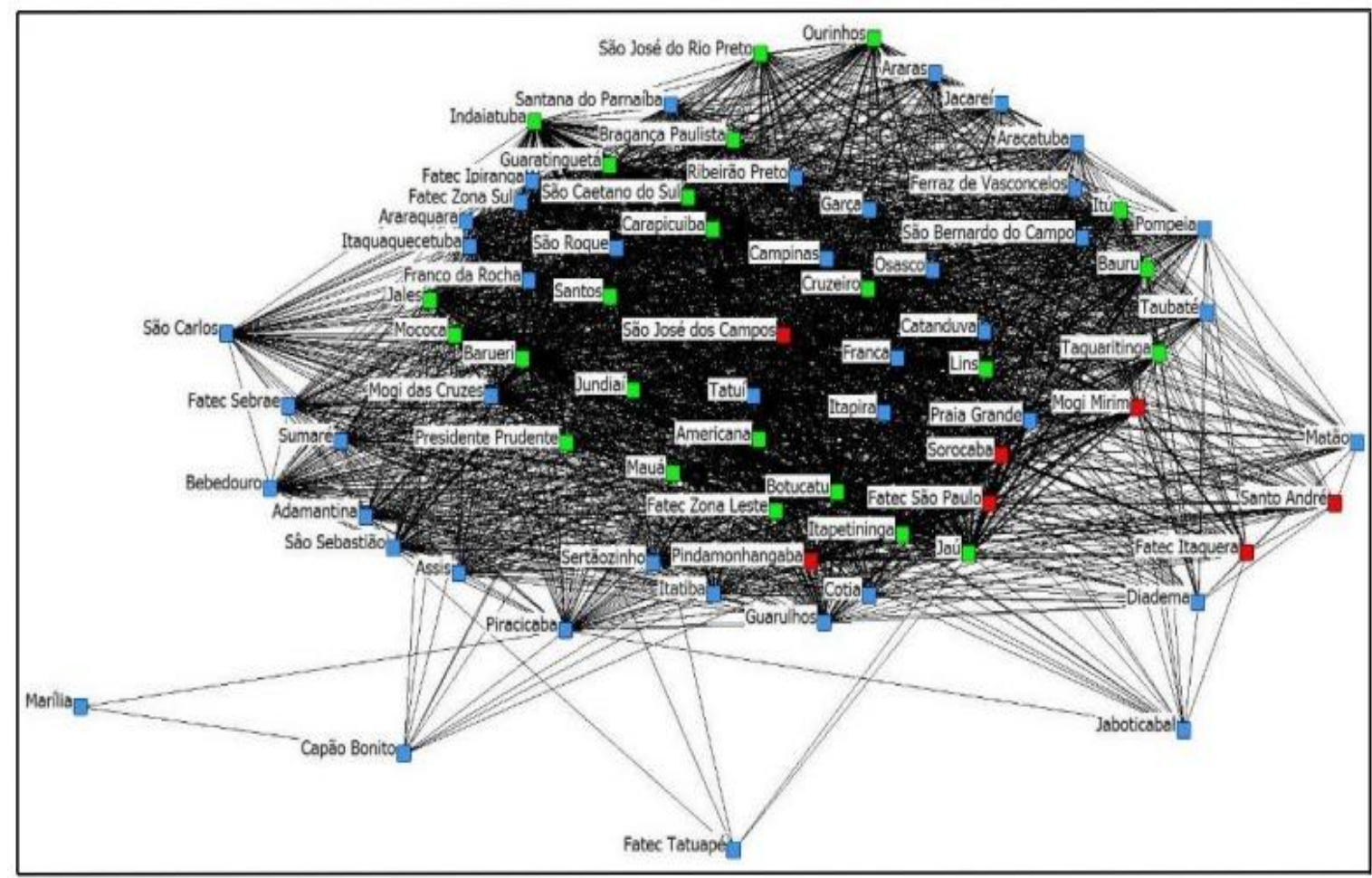

Fonte: Elaborado pelas autoras.

Desse modo, alinhada à observação de Granovetter (1973), observa-se que a análise da rede, com a visualização dos seus agrupamentos e sub-redes resultantes das proximidades de atuação tecnológica e geográfica, contribui para a identificação dos potenciais diálogos acadêmico-científicos e atividades em parcerias entre as unidades, dadas suas proximidades vocacionais, visando à construção de conhecimento e colaboração, seja voltada ao ensino, à pesquisa ou à atividade de extensão. Além disso, ao definir os agrupamentos, pode-se entender, segundo Amato Neto (2008), que há, por outro lado, repertórios de habilidades específicas que propiciam a disseminação de conhecimentos e podem gerar transformações sociais.

Destaca-se, ainda, que as unidades que oferecem maior quantidade de cursos podem ser consideradas potencialmente mais centrais na construção de parcerias na rede de atuação do CEETPS, como é o caso das Fatecs São Paulo (membro de G3) e Jaú (membro do agrupamento G2), com atuação em pelo menos seis eixos cada. 


\section{Considerações Finais}

O setor de Educação, mais especificamente com relação às IES, deve cumprir sua função, segundo o que estabelece a legislação pertinente. Por serem consideradas organizações que buscam permanecer no mercado altamente competitivo, elas oferecem modalidades de ensino superior específico, ou seja, cursos de graduação tecnológica, sendo o CEETEPS referência no estado de São Paulo.

Em decorrência das áreas em que atuam, os cursos são organizados em eixos tecnológicos e, dada a sua representatividade no desenvolvimento do conhecimento a ser empregado em ambientes laborais, seus cursos são definidos para cada cidade segundo a demanda das empresas locais e regionais.

Não obstante, há que se refletir acerca dos conhecimentos teóricos e práticos que são gerados pela comunidade acadêmica e muito importantes ao cenário mercadológico. Por esta razão, buscou-se analisar a rede das Faculdades de Tecnologia do CEETEPS, de modo a compreender sua composição, ou seja, suas ligações por meio das similaridades tecnológicas dos cursos por elas oferecidos. Considera-se que, ao contribuir para a visualização e mais amplo entendimento das características peculiares dos eixos tecnológicos e os respectivos cursos oferecidos pelas Fatecs, o mapeamento pode servir para a reflexão sobre modelos de gestão e a interação intrainstitucional em instituições multicampi, além de conjecturar questões relativas à robustez de algumas Unidades e às especificidades de outras. Desse modo, o gerenciamento pedagógico, científico e social pode ser analisado, permitindo a discussão de práticas administrativas que fomentam o crescimento do complexo educacional.

Neste estudo, o foco se deu como a exploração das potencialidades do universo de pesquisa, o CEETEPS, dada a representatividade da referida Instituição para o desenvolvimento socioeconômico do Estado. Esse fato requer a compreensão da dinâmica das atividades acadêmicas, suas especificidades e seus aportes que podem ser de interesse para a comunidade.

A relevância do estudo pode ser entendida em virtude de que a IES tecnológica com estrutura multicampi apresenta inúmeros desafios de ordem administrativa, o que requer a análise de suas fraquezas e fragilidades, exigindo o envolvimento dos gestores de cada unidade para que os objetivos almejados possam ser atingidos (CARVALHO; OLIVEIRA; LIMA, 2018).

Nesse sentido, o estudo revelou a presença de três agrupamentos de unidades da instituição analisada, definidos segundo suas similaridades de amplitude de atuação 
tecnológica e intensidade de cursos oferecidos. Vale ressaltar que aspectos, como forças e fraquezas dos grupos, poder de negociação, de gerenciamento da estrutura educacional, dentre outras questões, devem ser considerados.

Dada a natureza da IES estudada, a análise da sua rede de unidades e eixos tecnológicos contribuiu para a melhor visualização dos agrupamentos dentro da Instituição. Contudo, novas vertentes de estudo podem ser exploradas, visando a percepção das peculiaridades das Unidades, cenários que mereçam atenção, de forma a levantar e fortalecer as potencialidades que tornam o CEETEPS referência de educação tecnológica no estado de São Paulo.

Considera-se, ainda, importante salientar que as relações entre as unidades da instituição multicampi analisada foram baseadas em características em comum (no caso, oferecimento de cursos) e não em relações voluntárias (diretas) como em outros tipos de redes sociais (por exemplo, amizade, parceria universidade-empresa, coautoria, entre outras). Neste sentido, considera-se significativo observar que o significado de alguns conceitos e métricas tratadas nesta pesquisa podem ser distintos daqueles em que as relações são diretas nas redes estabelecidas. Desse modo, na rede gerada, a centralidade ou influência de uma unidade em relação às demais refere-se a uma sinalização aos gestores do potencial desta unidade para contribuição para o avanço da instituição multicampi em função das suas características relativas aos indicadores analisados.

Finalizando, considera-se que a análise de rede em conjunto com a análise de agrupamento pode ser interessante aos gestores das instituições por promoverem reuniões setoriais por área do conhecimento, visando fomentar atividades colaborativas, identificando outras Fatecs que poderiam atuar como polos/centros do fluxo da atividade colaborativa, ações que, certamente, favorecem o cenário produtivo do CEETEPS. Além disso, a análise dos agrupamentos na rede do Centro Paula Souza evidencia quais unidades oferecem cursos comuns. Cada Fatec instalada em um município possui abordagem em cenários mercadológicos específicos, razão pela qual os conhecimentos ali desenvolvidos podem ser enriquecidos com conhecimentos de docentes e alunos de outras unidades.

\section{Referências}

ANDRIOLA, W. B.; ARAÚJO, A. C. Uso de indicadores para diagnóstico situacional de Instituições de Ensino Superior. Ensaio: Avaliação e Políticas Públicas em Educação, Rio de Janeiro, v. 26, n. 100, p. 645-663, jul./set. 2018 
AMATO NETO, J. Redes de cooperação produtiva e clusters regionais: oportunidades para as pequenas e médias empresas. São Paulo: Atlas; Fundação Vanzolini, 2008.

AZEVEDO-FERREIRA, M.; MOTTA, G. S. A oferta tecnológica acadêmica da microrregião do sul fluminense: um estudo informétrico do Diretório dos Grupos de Pesquisa (DGP).

Revista Ciências Administrativas, Fortaleza. v. 22, n. 1, p. 225-254, 2016.

BAMPI, A. C.; DIEL, J.O. O modelo multicampi de universidade e suas relações com a sociedade. In: XIII Colóquio de Gestión Universitaria en Americas, 2013, Buenos Aires, 2013. Anais [...]. Colóquios Internacionais sobre Gestão Universitária. Santa Catarina, 2013. p. 1-15.

BONACCORSI, A.; DARAIO, C.; SIMAR, L. Advanced indicators of productivity of universities. An application of robust nonparametric methods to Italian Data. Scientometrics, Dordrecht, v. 66, n. 2, p. 389-410, 2006.

BRASIL. Lei n ${ }^{\circ}$ 9.394, de 20 de dezembro de 1996. Estabelece as diretrizes e bases da educação nacional. Diário Oficial da União, Seção 1, Brasília, DF, p. 27833, 23 dez. 1996.

BRASIL. Ministério da Educação. Cursos Superiores de Tecnologia. Brasília/DF, 2002. Disponível em: http://portal.mec.gov.br/cne/arquivos/pdf/CP032002.pdf. Acesso em: 6 set. 2019.

BRITTO, J. N. P. Cooperação interindustrial e redes de empresas. In: KUPFER, David; HASENCLEVER, Lia (Org.). Economia industrial: fundamentos teóricos e práticos no Brasil. 2. ed. Rio de Janeiro: Campus, 2002.

BRUNI, R. et al. Characterizing the Heterogeneity of european Higher Education Institutions Combining Cluster and Efficiency Analyses. In: 17th International Conference on Scientometrics \& Informetrics - ISSI 2019, 17., Roma. Proceedings [...]. Roma: ISSI, 2019. v. II, p. 2094-2105, 2019.

CARVALHO, H. A.; OLIVEIRA, O. S.; LIMA, I. A. Avaliação Institucional em uma universidade pública brasileira multicâmpus: processos e desafios na qualificação da gestão. Avaliação: Revista da Avaliação da Educação Superior (Campinas), Sorocaba, v. 23, n. 1, p. 217-243, mar. 2018.

CASTANHA, R.C.G.; GRÁCIO, M.C.C. Contribuição da estatística multivariada para a avaliação dos programas de pós-graduação no Brasil: um estudo na área da Ciência da Informação. Em Questão, Porto Alegre, v. 23, p. 180-195, 2017.

CENTRO ESTADUAL DE EDUCAÇÃO TECNOLÓGICA PAULA SOUZA. 2019. Disponível em: https://www.cps.sp.gov.br/. Acesso em: 05 set. 2019.

CRUZ, A. P. C. et al. Perfil das redes de cooperação científica: congresso USP de controladoria e contabilidade - 2001 a 2009. Revista Contabilidade \& Finanças-USP, São Paulo, v. 22, n. 55, p. 64-87, jan./abr. 2011. 
ESCALONA-FERNANDEZ, M. I. et al. Rede de colaboração científica entre universidades brasileiras: uma análise na área de odontologia. Brazilian Journal of Information Science, Marília, v. 6, n. 1, p. 16-38, jan./jun. 2012.

FUNDAÇÃO DE AMPARO À PESQUISA DO ESTADO DE SÃO PAULO. Indicadores de Ciência, Tecnologia e Inovação em São Paulo 2010. São Paulo, 2010. v. 1. Disponível em: http://www.fapesp.br/indicadores/2010/volume1/cap2.pdf. Acesso em: 5 set. 2019.

GARCIA, R.I.; MATIAS, M. Rede de relações entre institutos federais de educação e as universidades públicas do sul do Brasil. Em Questão, Porto Alegre, v. 25, n. 2, p. 166-189, maio/ago. 2019.

GIL, A. C. Como elaborar projetos de pesquisa. 5. ed. São Paulo: Atlas, 2010.

GONZALEZ, R.V.D.; MARTINS, M.F.; MELO, T.M. Gestão do conhecimento: tipologia a partir de fatores contextuais da organização. Transinformação, Campinas, v. 30, n.2, p. 249266, 2018.

GRÁCIO, M.C.C. Análises relacionais de citação para a identificação de domínios científicos. Marília: Oficina Universitária; São Paulo: Cultura Acadêmica, 2020.

GRÁCIO, M. C. C.; OLIVEIRA, E. F. T. Produção e Comunicação da Informação em CT\&I - GT7 da ANCIB: análise bibliométrica no período de 2003/2009. In: Encontro Nacional de Pesquisa da ANCIB (ENANCIB), 2010, Rio de Janeiro. Anais [...]. Rio de Janeiro: ANCIB, 2010.

GRANOVETTER, M. S. The strength of weak ties. American Journal of Sociology, Chicago, v. 78, n. 6, p. 1360-1380, maio 1973.

HAIR, F.J. et al. Multivariate Data Analysis. 7th ed. New Jersey: Prentice Hall, 2009.

HILÁRIO, C. M.; GRÁCIO, M. C. C. Colaboração científica na temática "Redes Sociais": análise bibliométrica do Enancib no período 2009-2010. Revista EDICIC, Marília, v. 1, n. 4, p. 363-375, 2011.

LAUXEN, S.L. Universidade multicampi. In: Morosini, M. (Coord). Enciclopédia de pedagogia universitária: glossário. Brasília: INEP/MEC, 2006. v. 2

MAPAS DE SÃO PAULO. [20--]. Disponível em: https://www.mapasparacolorir.com.br/mapa-estado-sao-paulo.php. Acesso em: 5 set. 2019.

MARTELETO, R. M. Análise de redes sociais - aplicação nos estudos de transferência da informação. Ciência da Informação, Brasília, v. 30, n. 1, p. 71-81, jan./abr. 2001.

MOLINA, J.L.; AGUILAR, C. Redes sociales y antropologia: um studio de caso (redes personales y discursos étnicos entre jóvenes em Sarajevo). In: LARREA KILLINGER, C.; ESTRADA, F. Antropologia en un mundo en transformación. Barcelona: Universidad de Barcelona. Servicio de Información, 2004, 176 p. 
MORAES, M.G.; SOUZA, L.A. Análise da produção do conhecimento da UNIRIO com a identificação de clusters. In: Encontro Nacional de Pesquisa em Ciência da Informação (ENANCIB), 18., 2017, Marília. Anais [...]. Marília: ENANCIB, 2017.

NEWMAN, M. E. J. The structure of scientific collaboration networks. Proceedings of National Academy Sciences, Santa Fé, p. 404-409, 2001.

NEZ, E. Os dilemas da gestão das universidades multicampi no Brasil. Revista GUAL, Florianópolis, v. 9, n. 2, p. 131-153, maio 2016.

OLAVE, M. E. L.; AMATO NETO, J. Redes de cooperação produtiva: uma estratégia de competitividade e sobrevivência para pequenas e médias empresas. Revista Volume, São Carlos, v. 8, n. 3, p. 289-318, dez. 2001.

OLIVEIRA E SILVA, A. B. et al. Análise de redes sociais como metodologia de apoio para a discussão da interdisciplinaridade na Ciência da Informação. Ciência da Informação, Brasília, v. 35, n. 1, p. 72-93, jan./abr. 2006.

OTTE, E.; ROUSSEAU, R. Social Network Analysis: a powerful strategy, also for the information sciences. Journal of Information Science, Thousand Oaks, v. 26, n. 6, p.441453, 2002.

SANTANA, G. H. C. et al. Informação científica e tecnológica em Instituições de Ensino Superior (IES): indicadores de grupos de pesquisa (GP) de memória. Ponto de Acesso, Salvador, v. 8, n.1, p. 56-80, abr. 2014.

SANTIN, D. M. Avanços e perspectivas da informetria e dos indicadores multidimensionais na análise de fluxos da informação e estruturas do conhecimento. Encontros Bibli: Revista Eletrônica de Biblioteconomia e Ciências da Informação, Florianópolis, v. 16, n. 32, p. 107$122,2011$.

TOMAÉL, M. I.; MARTELETO, R. M. Redes sociais: posições dos atores no fluxo de informação. Encontros Bibli: Revista Eletrônica de Biblioteconomia e Ciência da Informação, Florianópolis, n. esp. 1.sem, 2006.

VANZ, S. A. S. et al. Rankings universitários internacionais e o desafio para as universidades brasileiras. Encontro Bibli: Revista Eletrônica de Biblioteconomia e Ciência da Informação, Florianópolis, v. 23, n. 53, p. 39-51, set./dez., 2018.

WASSERMAN, S.; FAUST, K. Social network analysis: methods and applications. New York, USA: Cambridge University Press, 1994. 


\title{
Mapping of higher education units in multicampi institutions: analysis of technological proximity in Centro Estadual de Educação Paula Souza
}

\begin{abstract}
Higher Education Institutions are considered important pillars for scientific and technological development. In this context, Centro Estadual de Educação Tecnológica Paula Souza -a multicampi educational institution- is composed of 73 technology colleges allocated in São Paulo state. This study aims to analyze the proximities among Centro Paula Souza's units according to their technological vocations, in order to visualize clusters formed from their similarities. As a methodological approach to map the similarity network between the educational units, social network analysis and cluster multivariate statistical analysis are adopted. There are three clusters, from which it is possible to visualize the potential for interaction between the units, their strengths, common aspects, and peculiarities. The results provide input to the decision-making of the institution's academic-scientific management as well as a method of analysis for others with a similar structure.
\end{abstract}

Keywords: Clusters in Multicampi Higher Education Institutions. Social Network Analysis. Informetrics.

Recebido: $16 / 11 / 2020$

Aceito: 05/03/2021

\section{Declaração de autoria}

Concepção e elaboração do estudo: Regina Ferreira da Rocha e Maria Cláudia Cabrini Grácio

Coleta de dados: Regina Ferreira da Rocha e Maria Cláudia Cabrini Grácio

Análise e discussão de dados: Regina Ferreira da Rocha e Maria Cláudia Cabrini Grácio

Redação e revisão do manuscrito: Regina Ferreira da Rocha e Maria Cláudia Cabrini Grácio

\section{Como citar}

ROCHA, Regina Ferreira da; GRÁCIO, Maria Cláudia Cabrini. Mapeamento das unidades de ensino superior em instituições multicampus: análise das proximidades tecnológicas no Centro Estadual de Educação Paula Souza. Em Questão, Porto Alegre, v. , n. .. 2021.

\footnotetext{
${ }^{1}$ SCOTT, J. Social network analysis: a handbook. $2^{\text {nd }}$ ed. London: Sage Publications, 2000. Apud Hilário; Grácio (2011).
} 